\title{
COMPUTER SIMULATION AND ANALYSIS OF THE PARAMETERS OF THE DRAWING PROCESS OF THIN WIRE FROM THE ALLOY Pd-5Ni
}

\author{
Sergey SIDELNIKOV ${ }^{1}$, Kristina BINDAREVA ${ }^{1}$, Ekaterina LOPATINA ${ }^{1}$, \\ Viktor LEONOV ${ }^{1}$, Denis VOROSHILOV ${ }^{1, \mathrm{a}}$ *, Olga LEBEDEVA ${ }^{1}$, \\ Edvard RUDNITSKIY ${ }^{1}$, Vladimir LOPATIN ${ }^{1}$ \\ ${ }^{1}$ Siberian Federal University, Russia, 660025, Krasnoyarsk, Krasnoyarskiy Rabochiy ave., 95 \\ ae-mail: sibdrug@mail.ru
}

Keywords: precious metal alloys, palladium, nickel, drawing, deformation modes, temperature, stresses, mechanical properties, safety factor.

\begin{abstract}
This article represent the results of studies of the drawing thin wire from the alloy Pd$5 \mathrm{Ni}$ process. The studies used the software developed by the authors using the methods of calculating the drawing process and the computer model implemented in the DEFORM 3D software package. By way of calculation, a drawing route was determined, including 14 transitions, and the efforts of deforming the metal were found when producing wire with a diameter of 0.075. For this mode of deformation processing using the DEFORM 3D software package, we simulated the drawing process and established the temperature and stress distribution over the volume of the workpiece. The simulation results confirmed that the calculated safety factor for drawing is in the range of 2.85-3.43, which ensures a stable process of deformation of the metal without breaks and, as a consequence, an increase in productivity and yield of the suitable metal. Experimental studies have confirmed the adequacy of the developed model, so it can be used to analyze the process of drawing wire from other precious metal alloys. The results of the research are recommended to improve the production technology of thin wire from the alloy $\mathrm{Pd}-5 \mathrm{Ni}$ for the manufacture of catalytic gripping grids.
\end{abstract}

\section{Introduction}

In the manufacture of longish deformed semi-finished products from alloys of precious metals due to improper distribution of the degrees of deformation (drawing ratio) over transitions and hardening of the metal, significant tensile stresses occur, which can lead to wire breaks. Especially this problem is typical for thin wire drawing with a diameter of up to $0.075 \mathrm{~mm}$. This leads to a decrease in productivity, low yield of metal and, as a consequence, a decrease in technical and economic indicators of production.

$\mathrm{Pd}-5 \mathrm{Ni}$ alloy was chosen as a material for research, the machining technology, the properties and structure of which are still insufficiently studied and poorly covered in the scientific and technical literature [1-5]. This alloy is widely used in the manufacture of catch nets, which have a woven structure and are installed after the catalyst grids. These nets are designed to capture platinum and rhodium during operation. The use of such grids on the units for the production of hydroxylamine and nitric acid [6-9] reduces the attachment of platinum and rhodium, as well as their specific losses. These grids are made of thin wire with diameters of 60 , 76 and 90 microns.

The chemical composition of the alloy, which was used in the studies presented in table 1.

Table 1 - The chemical composition of the alloy $\mathrm{Pd}-5 \mathrm{Ni}$

\begin{tabular}{|c|c|c|c|c|c|c|c|c|c|}
\hline \multicolumn{2}{|c|}{ Base metals, \% } & \multicolumn{9}{|c|}{ Impurities, \% } \\
\hline $\mathrm{Pd}$ & $\mathrm{Ni}$ & $\mathrm{Pt}$ & $\mathrm{Rh}$ & $\mathrm{Au}$ & $\mathrm{Cu}$ & $\mathrm{Al}$ & $\mathrm{Co}$ & $\mathrm{Fe}$ & $\mathrm{Mg}$ \\
\hline 94.96 & 5.03 & 0.0039 & 0.0008 & 0.0003 & 0.0004 & 0.0007 & 0.0008 & 0.0008 & - \\
\hline
\end{tabular}


The purpose of this work, therefore, is to study the modes of drawing a thin wire from the alloy Pd-5Ni with the help of authoring software and computer simulation of the process.

\section{Methods of carrying out researches}

The analysis of the existing processing modes, performed using the PROVOL software package [10] using the techniques outlined in the tutorial [11], made it possible to calculate the route of drawing, force $P_{\text {draw }}$ and determine the safety factor $\eta$ (Table 1). The mechanical properties of the wire were determined by the method of stretching, which were carried out on an "Inspecttableblue" testing machine with a developed force of $5 \mathrm{kN}$ [12].

Table 2 - Technological mode thin wire drawing alloy Pd-5Ni

\begin{tabular}{|c|c|c|c|c|c|c|}
\hline № & $\begin{array}{c}\text { Diameter, } \\
\mathrm{mm}\end{array}$ & $\begin{array}{c}\text { Drawing } \\
\text { ratio, } \\
\lambda_{\text {singl }}\end{array}$ & $\begin{array}{c}\text { Deformation } \\
\text { degree, } \\
\varepsilon_{\text {singl }, \%}\end{array}$ & $\begin{array}{c}\text { Ultimate tensile } \\
\text { strength } \\
R_{m}, \mathrm{MPa}\end{array}$ & $\begin{array}{c}\text { Safety } \\
\text { factor, } \\
\eta\end{array}$ & $\begin{array}{c}\text { Drawing } \\
\text { force } \\
P_{\text {draw }}, \mathrm{kN}\end{array}$ \\
\hline 1 & 0.163 & 1.08 & 7.0 & 607 & 3.28 & 3.9 \\
\hline 2 & 0.153 & 1.13 & 11.5 & 618 & 3.14 & 3.6 \\
\hline 3 & 0.144 & 1.14 & 11.9 & 625 & 3.08 & 3.3 \\
\hline 4 & 0.134 & 1.15 & 12.7 & 637 & 2.96 & 3.0 \\
\hline 5 & 0.125 & 1.15 & 13.0 & 658 & 2.91 & 2.6 \\
\hline 6 & 0.116 & 1.15 & 13.3 & 670 & 2.87 & 2.3 \\
\hline 7 & 0.108 & 1.16 & 13.4 & 685 & 2.85 & 2.0 \\
\hline 8 & 0.101 & 1.14 & 12.6 & 691 & 2.97 & 1.7 \\
\hline 9 & 0.095 & 1.14 & 12.3 & 715 & 3.02 & 1.5 \\
\hline 0 & 0.089 & 1.14 & 11.9 & 725 & 3.08 & 1.3 \\
\hline 11 & 0.084 & 1.13 & 11.5 & 734 & 3.14 & 1.1 \\
\hline 13 & 0.079 & 1.12 & 10.7 & 740 & 3.28 & 0.9 \\
\hline 14 & 0.075 & 1.11 & 9.9 & 750 & 3.43 & 0.8 \\
\hline
\end{tabular}

For the calculated drawing mode, as applied to the production of thin wire from the Pd$5 \mathrm{Ni}$ alloy, computer simulation was performed in the Deform-3D software package and the form-changing, stress-strain state of the metal, and temperature processing conditions were studied.

To simulate the process of drawing, the following initial data, initial and boundary conditions were adopted:

- working tools were portages with a calibrating zone with a diameter of $0.163 \mathrm{~mm}$ to $0.075 \mathrm{~mm}$, the angle of the die $7^{\circ}$;

- annealed wire with a diameter of $0.169 \mathrm{~mm}$ and a length of $10 \mathrm{~mm}$ from alloy Pd-5Ni was used as a workpiece;

- the initial temperature of the workpiece was $20^{\circ} \mathrm{C}$;

- the number of calculation steps was $600-1250$ with a step of $0.028-0.012 \mathrm{~mm}$.

- drawing speed $10000 \mathrm{~mm} / \mathrm{s}$;

- the conditions of contact interaction between the workpiece and the die were accepted according to the Amonton-Coulomb law with a friction index of 0.08 .

\section{Results and its discussion}

The construction of geometric three-dimensional models of dies and billets (Fig. 1) was carried out in the SolidWorks software package, after which they were imported into the software complex DEFORM-3D. 


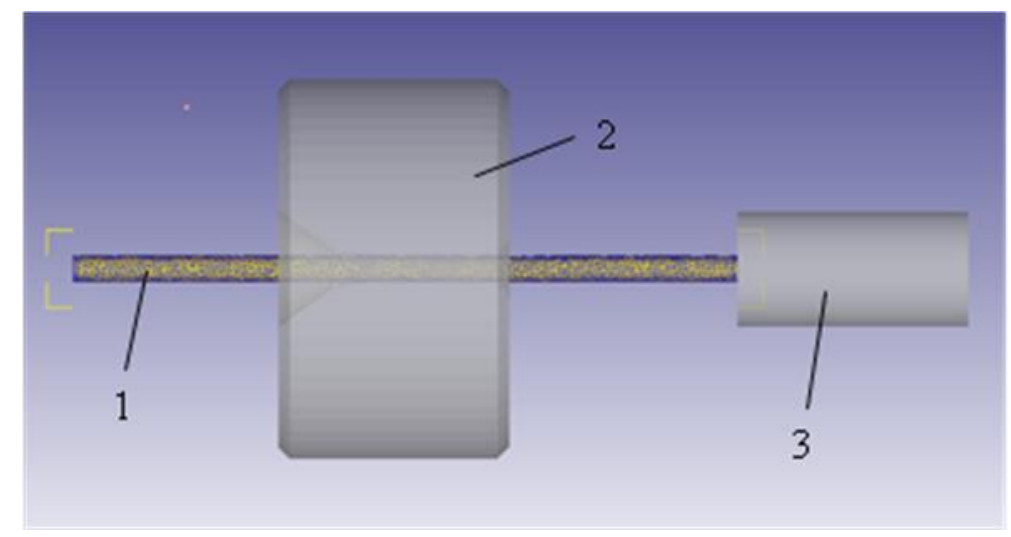

Fig.1.3D model tool and workpiece for drawing:

1 - workpiece; 2 - drawing tool; 3 - grab

The simulation results made it possible to trace the metal forming in the process of drawing (Fig. 2), to determine the temperature of the metal and the value of the drawing voltage for a given route. It was found that in the deformation zone, the wire is heated to $35-40{ }^{\circ} \mathrm{C}$, and the temperature is distributed evenly over the cross section of the metal (Fig. 2). Generated heat is formed due to friction forces, and contributes to the heating in the first place of the peripheral and then the central layers of the wire. This process affects the magnitude of the resistance to deformation, reducing it, which should be considered when analyzing changes in the properties of the wire in the process of drawing.

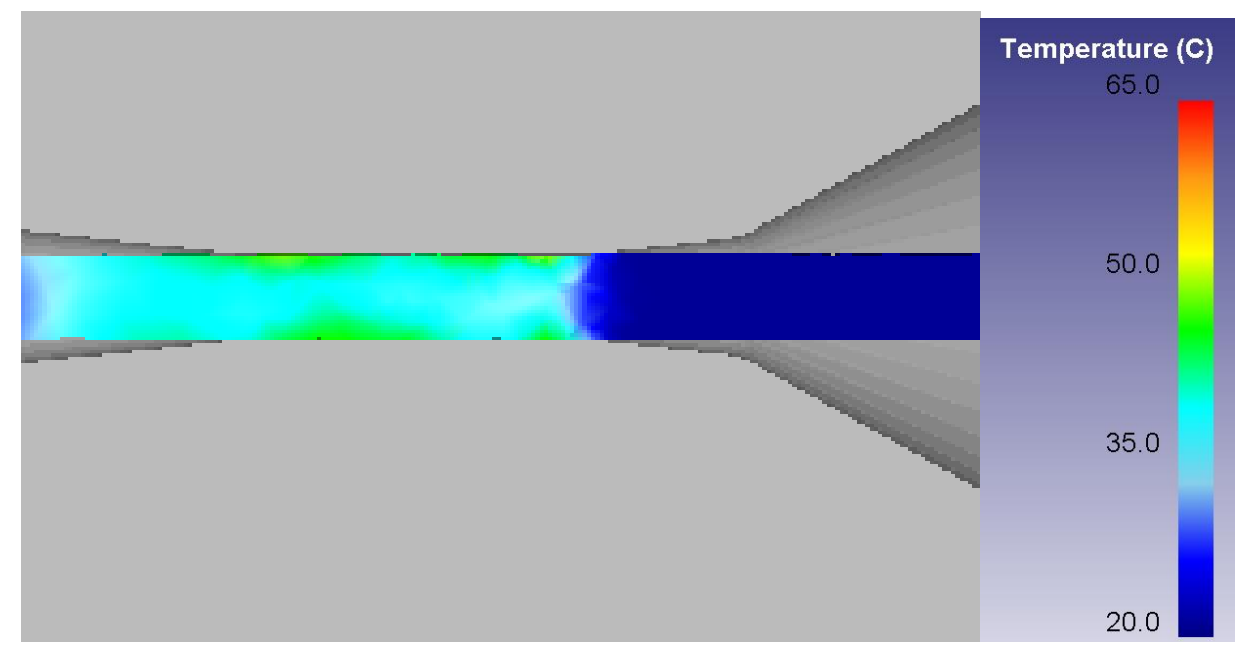

Fig. 2. Forming metal and its temperature distribution during drawing

The stress distribution in the deformation zone during drawing is shown in fig. 3. Analysis of fig. 3 shows that the maximum stresses are realized in a metal located in the gauge zone of the die, which fully corresponds to the traditional concepts of the theory of metal forming. The maximum stress value reaches $300 \mathrm{MPa}$, and average values are in the range of 250-280 MPa. Thus, the magnitude of the stresses does not exceed the ultimate tensile strength for wires of these sizes, and their ratio determines the safety factor, which is in the range 2.853.43 (table 2). Therefore, it can be argued that the proposed deformation processing modes will not lead to wire breaks during drawing. 


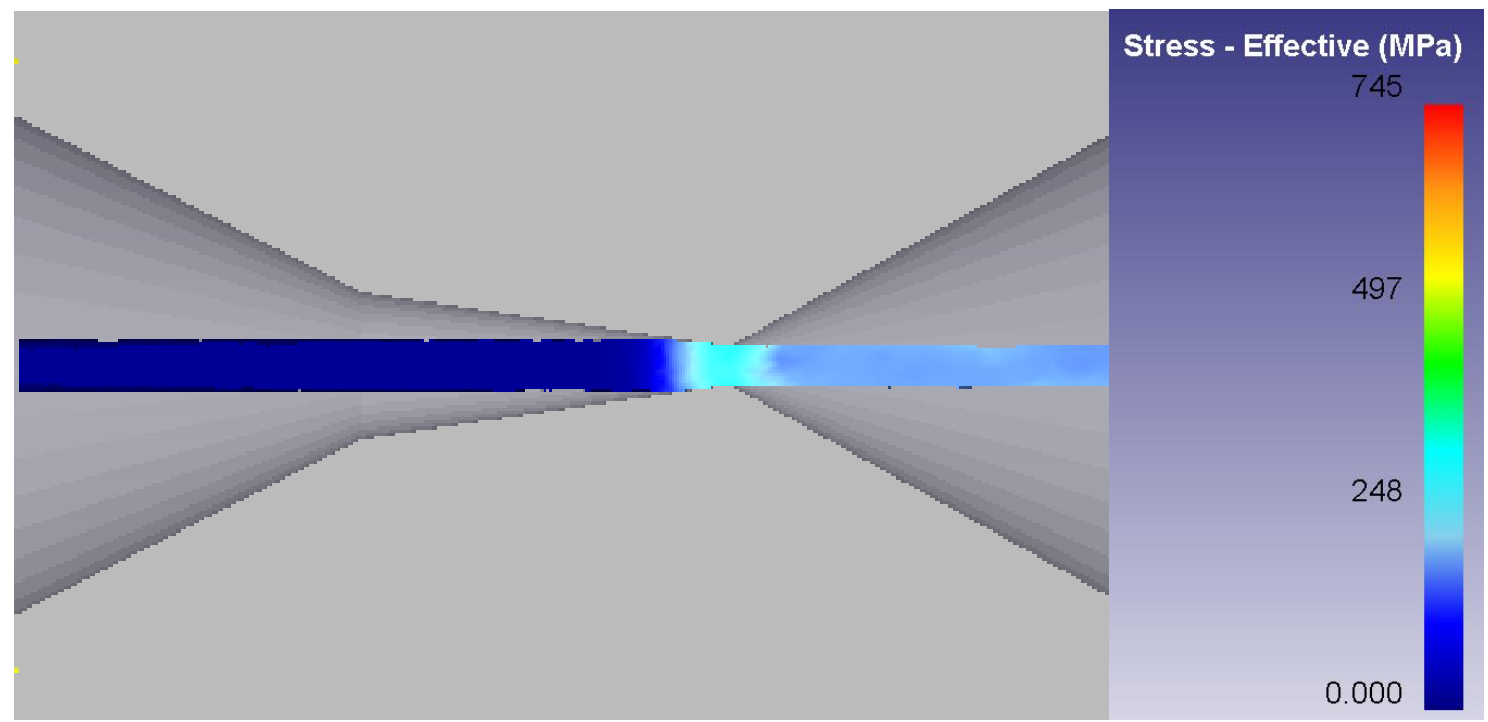

Fig. 3. Stress distribution in the deformation zone

Experimental studies [12] of the drawing process confirmed the simulation results, so the developed model can be considered adequate and with its help analyze the deformation modes of wire drawing for precious metal alloys.

\section{Conclusion}

Studies on the process of drawing thin wire from the alloy Pd-5Ni made it possible to draw the following conclusions. The mode of wire drawing with a diameter of $0.075 \mathrm{~mm}$ calculated from the use of copyright software from a billet with a diameter of $0.169 \mathrm{~mm}$ makes it possible to obtain high-quality products for the manufacture of catch grids of catalytic systems. The simulation of the process of drawing according to these modes made it possible to establish that the deformation of the metal proceeds steadily with an increase in the temperature of the metal in the deformation zone to $35-40{ }^{\circ} \mathrm{C}$. The magnitude of the calculated drawing stress does not exceed the ultimate tensile strength for wires of these sizes, and the safety factor is in the range of 2.85-3.43. This makes it possible to assert that the process of drawing fine wire from the alloy Pd-5Ni will be implemented without breaks, which was confirmed by experimental data in production conditions. The research results can be recommended to improve the technology of manufacturing wire for fabric catching grids of catalytic systems.

\section{References}

[1] Sidelnikov S.B., Konstantinov I.L., Dovzhenko N.N. [and others]. Production of jewelry from precious metals and their alloys: a textbook. 2nd ed. M.: INFRA-M, 2016.

[2] Novikov I.I, Zolotorevskiy V.S., Portnoy V.K. [and others] Metal science: textbook in $2 \mathrm{t}$. T1. Fundamentals of Metal Science. Moscow: Publ. MISiS, 2014.

[3] Konstantinov I.L. Materials science of precious metals: tutorial. Krasnoyarsk: IPK SFU, 2009.

[4] Ivanović T.A., Trumić B.T., Ivanov S.Lj., Marjanović S.R., Zrilić M.M., Volkov-Husović T.D., Petković B.B. Optimisation of the Recrystallisation Annealing Regime of Pd-5Ni Alloy. Johnson Matthey Technology Review. 60(1) (2016) 31-38.

[5] Pavlov E.A., Gurskaya V.Yu., Gushchinskiy A.A., Efimov V.N. Justification and selection of the cooling mode of the alloy PdNi-5 during the solidification of the ingot. Tsvetnye metally. 11 (2010) 46-50.

[6] Il'in A.P., Kunin A.V., Il'in A.A. Nitric acid production: a tutorial. Ivan. State chem.-tech. Un-ty. Ivanovo, 2011. 
[7] Korobochkin V.V. Nitric Acid Technology: A Tutorial. Tomsk: Publ. Tomsk polytech. Unty, 2012.

[8] Karavaev M.M., Zasorin A.P., Kleshchev N.F. Ammonia catalytic oxidation. M: Chemistry, 1983.

[9] Olevskiy V.M. Production of nitric acid in units of high unit capacity. M: Chemistry, 1985.

[10] Certificate of state registration of the computer program PROVOL №2015612273 RF / S.B. Sidelnikov, S.V. Belyaev, O.S. Lebedeva, Yu. D. Ditkovskaya, E.S. Leontieva, E.A. Rudnitsky, A.S. Solyanikova. Patento owner of FGAOU VPO "Siberian Federal University."- № 2014663306; claimed. 12/19/2014; publ. 02/16/2015.

[11]Ivanov E.V. Drawing technology: teaching aid. Krasnoyarsk: SibFU, 2012.

[12] Bindareva K.A. The study of the mechanical properties of semi-finished products from alloy PdNi-5 with varying degrees of purity. Prospect Svobodny - 2018: International Student Conference Proceedings. Krasnoyarsk: SibFU, (2018) 1059-1061. 